\title{
Panorama Profissional
}

\section{Projeto de Reestruturação Operacional do Corredor Baixada Fluminense-Rio de Janeiro}

\section{Carlos David Nassi}

Programa de Engenharia de Transportes - COPPE/UFRJ

A COPPE foi contratada pelo Departamento de Transportes Rodoviários (DETRO-RJ) para elaborar um plano funcional preliminar relativo ao corredor Baixada Fluminense - Rio de Janeiro, já que será concluída no ano de 1993 a segunda etapa da obra da Linha Vermelha. A con. clusão desta obra pode trazer reflexos importantes para o transporte público que serve a Baixada Fluminense. Poder-se-ia pensar em reestruturar o sistema de ônibus que serve esta região. A seguir descrevem-se os objetivos do trabalho, as etapas do estudo, bem como as principais características do sistema.

\section{Objetivo}

Elaboração de um Plano Funcional Preliminar, a partir de informações pré-existentes no DETRO-RJ, na CODERTE, no DER-RJ e no DCV além, eventualmente, de outras a serem recolhidas e/ou pesquisadas no campo, para a implantação de um Sistema Tronco Alimentador, com base nos corredores da Rodovia Presidente Dutra, Rodovia Washington Luiz, Av. Presidente Kennedy e Av. Automóvel Clube, além da Linha Vermelha.

\section{Etapas}

A - Coleta e análise das informações básicas existentes no DETRO-RJ, DCV, CODERTE, DER-RJ e no Plano de Transporte de Massa, além de eventuais contagens volumétricas de tráfego.

B - Tratamento das informações coletadas na primeira 
etapa com elaboração de mapas adequados que possibilitem visualizar os itinerários principais das linhas componentes do sistema Centro-Baixada Fluminense.

C - Formulação de proposições para reestruturação operacional na área de estudo para apoiar processo de discussão com os diversos agentes dos sistemas visando a escolha de uma alternativa factível para detalhamento.

D - Desenvolvimento, em nível de plano funcional do sistema tronco alimentador, compreendendo:

1. Descrição Operacional do Novo Sistema

Apresentação de quadro da oferta constando o "pré-dimensionamento" da frota necessária para operação do sistema racionalizado de maneira a se mensurar os ganhos de produtividade e qualidade do serviço.

\section{Terminais de Transbordo}

2.1 Proposição dos locais onde serão implantados os terminais de transferência a partir de atributos identificados durante os estudos como condicionantes da escolha modal.

\section{Terminal Américo Fonte- nelle}

3.1 Formulação de alternati- vas de circulação dos acessos incluindo-se análise da capacidade das ligações do Terminal Américo Fontenelle à Linha Vermelha utilizando-se as contagens de tráfego disponíveis.

3.2 Adequação do "lay-out" atual às necessidades do novo sistema e compatibilização com os projetos ora em discussão no âmbito da SECTRAN e da CBTU.

4. Tarifação-Integração/Gestão

Apresentação sucinta do estado da arte no cenário brasileiro indicando os modelos factíveis de serem implantados.

\section{Principais características do sistema}

A Baixada Fluminense é servida por 29 empresas de ônibus. Dentre estas, apenas 20 empresas foram analisadas neste trabalho por serem de interesse para os corredores selecionados. Nem todas as linhas destas 20 empresas servem os corredores selecionados. Apenas 129 linhas de ônibus foram aqui analisadas.

Para este trabalho foram levados em consideração os seguintes corredores: Rodovia Presidente Dutra, Rodovia Wa- 
shington Luiz, Av. Presidente Kennedy e Av. Automóvel Clube. Atualmente estes corredores vão interligar-se com a Av. Brasil que concentra a maior parte do tráfego em direção ao centro do Rio de Janeiro.

Num futuro próximo, haverá uma opção, com a conclusão das obras da Linha Vermelha.

A frota utilizada nestas linhas intermunicipais é de 1.225 ônibus.

São realizadas $370.360 \mathrm{via}$ gens/mês, correspondendo ao transporte de 12.558 .956 passageiros/mês. Isto corresponde a aproximadamente 468.600 passageiros transportados por dia útil.

A operação destas linhas intermunicipais inicia-se a partir das 5 horas.

As viagens realizadas por tais linhas têm uma extensão que varia de $6,3 \mathrm{~km}$ (ligando dois subúrbios próximos) a $81,4 \mathrm{~km}$ (ligando o terminal Américo Fontenelle a Andorinhas - Subúrbio do Rio de Janeiro).

A quase totalidade dos itinerários destas linhas é em vias pavimentadas.

É importante, no entanto, distinguir dois tipos de linhas de interesse para este trabalho, a saber: linhas radiais (que ligam o centro do Rio de Janeiro a algum município vizinho), e linhas ali- mentadoras (que ligam dois subúrbios do Rio de Janeiro, tocando ou usando parcialmente os corredores em análise).

As linhas radiais que se dirigem ao centro do Rio de Janeiro utilizam três terminais distintos, a saber: Américo Fontenelle, Praça Mauá e Praça XV.

O terminal Américo Fontenelle é o ponto de maior concentração das linhas intermunicipais integrantes do corredor Centro do município do Rio de Janeiro Baixada Fluminense.

Juntamente com os terminais da STU/RJ, do Metrô/RJ e o terminal de linhas rodoviárias urbanas situado em área vizinha, esse conjunto consitui o mais importante ponto de integração de transporte da Região Metropolitana do Rio de Janeiro.

O Terminal Rodoviário Américo Fontenelle está localizado no Bairro da Gamboa, área central do município do Rio de Janeiro.

O terminal é circundado pelas ruas Barão de São Félix, Bento Ribeiro, Coronel Aldomaro Costa e Alfredo Dolabela Portela.

$\mathrm{O}$ acesso dos ônibus ao terminal é efetuado pelas ruas Barão de São Féïix e Alfredo Dolabela Por tela. A primeira das duas alterna 
tivas supramencionadas sendo utilizadas pelos veículos procedentes da Rua Senador Pompeu e a segunda daqueles provenientes do sistema Bento Ribeiro - Cel. Aldemaro Costa.

Táxis e veículos de passageiros também têm acesso ao terminal pelo trajeto formado pelas ruas Bento Ribeiro e Cel. Aldemaro Costa.

Cabe ainda mencionar o intenso fluxo de pedestres que se destina ao terminal proveniente dos demais terminais de transporte existentes na área. Esta situação assume uma condição de destaque no período compreendido pelas últimas horas da tarde e primeiras horas da noite dos dias normais de trabalho, ocorrendo fluxo inverso no período da manhã.

O fluxo de pedestres utilizase, em grande parte, de acesso subterrâneo correspondente à área do terminal ferroviário Pedro II.

O terminal compreende atualmente um conjunto de cinco plataformas, longitudinalmente às quais estacionam os ônibus.

Segundo a CODERTE, diariamente são efetuadas quase 6.000 viagens redondas ao terminal Cel. Américo Fontenelle (em outubro de 1992). A esse total de viagens correspondia, na mesma época, o expressivo patamar de 252 mil passageiros sendo diariamente servidos pelo terminal. 